\title{
IDENTIFICACIÓN Y ANÁLISIS: MASCULINIDADES Y FEMINISMOS EN LA TIERRA DEL PROFETA, RAÚL DORRA
}

\author{
IDENTIFICATION AND ANALYSIS: MASCULINITIES \\ AND FEMINISMS IN THE LAND OF THE PROPHET, \\ RAÚL DORRA
}

Cahuaré Arce Jesica

\section{Resumen}

El presente artículo parte de una problemática detectada durante el proceso de investigación de la tesis de maestría, titulado: "Subjetividad y formación de creencias en el proceso cotidiano de la significación: análisis cultural de La tierra del profeta ${ }^{1}$, Raúl Dorra"; problemática que radica en la identificación de una serie de elementos, que permiten afirmar la existencia de un cuestionamiento a los esquemas tradicionales asociados con los roles de lo masculino y lo femenino. Si

1 Dorra, R. (1997) La tierra del profeta. México: UAM

Una mujer samaritana a la que Jesús había pedido beber y a quien le dijo que él podrá ofrecerle el "agua viva", impresionada por aquellas palabras a la hora de su muerte encamina a Abimael tras las huellas del aquel hombre, quien ha sido crucificado en Jerusalén, pero quedan sus discípulos. Mientras busca la lejana casa de Pedro, Abimael, hijo de la samaritana y de un guerrillero zelota recluido en prisión, recorre las ciudades de Galilea tratando de descifrar una identidad cada vez más enigmática. ¿Era el hombre un profeta como Elías o como el Bautista? ¿Era un hablador díscolo y quebrador de la ley? ¿Era un astuto o un ingenio milagrero? Los testimonios que obtiene son contradictorios. Más que de la identidad de Jesús, hablan del mundo hebreo de entonces, de los grupos que lo integran y de las tensiones que enfrentan; de la política ejercida por el poder romano y de la difundida espera de una convulsión final. La travesía es vivida por Abimael eje articulador que muestra los diversos matices de los procesos cotidianos en disputa por el reconocimiento del sentido. Revelando en su peregrinar a una sociedad fuertemente virilizada. 


\section{Introducción}

La presente investigación nace de múltiples lecturas realizadas a las obras del escritor argentino Raúl Dorra, específicamente al tratamiento que le da a las representaciones femeninas y masculinas, reconstruidas desde el texto literario. Llama la atención la intencionalidad que el autor mantiene en analizar y recrear el papel de las feminidades y masculinidades. Cabe señalar que, en este trabajo, se aludirá desde un primer acercamiento; ya que he elegido como punto de llegada esta novela porque considero que marca las tendencias en la perspectiva feminista tratada desde la resignificación de personajes femeninos, presentes en la biblia (RVR, 1960).

Aunado a ello, la importancia de hacer investigación no solamente de feminismos literarios escritos por feministas, mujeres reiteradas a través del discurso literario; sino realizar nuevas lecturas de escenarios y prácticas presentes en materia de género; $y$, poder abonar en un terreno poco explorado: feminismos desde las masculinidades.

Los estudios de género han abierto esclusas para la pluralidad de amplios corrientes críticas centrados en la reflexión, acerca de las construcciones sociales que atribuyen actitudes y prácticas a los sujetos, quienes históricamente han sido coartados por su sexo. Esto representa que, de acuerdo con criterios fisiológicos (no del todo válidos, sino manipulados culturalmente desde los cánones de poder androcéntrico), se han hecho explícita las formas específicas y permitidas de ser y hacer en sociedad, lo cual implica, por supuesto, los límites de las realizaciones en cada uno de los roles.

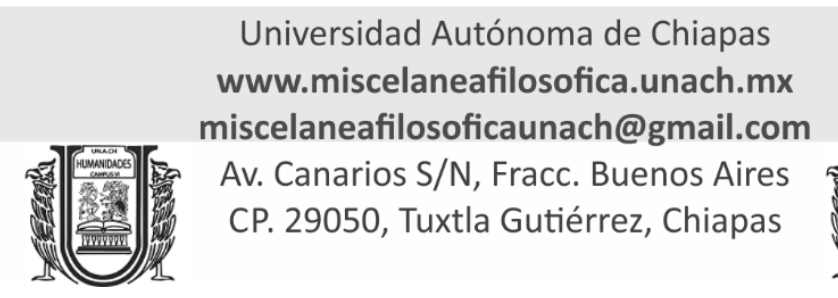


| Cuatrimestral Facultad de Humanidades Campus VI Reserva de Derechos al Uso Exclusivo No.: 04-2018-060814012200-203| ISSN: 2594-1755 Año II | Número 6 | Mayo- Agosto 2019

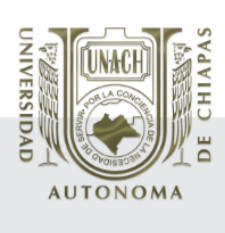

\section{ARTÍCULOS}

No obstante, ya es un hecho admitido que estas elaboraciones son producto de los acuerdos sociales y no rasgos inherentes y por tanto indisociables del individuo. Tal como lo afirma Torres (2007: 228): “La feminidad y la masculinidad pertenecen al orden de lo imaginario y lo simbólico, es decir, al orden de las representaciones". La claridad de esta perspectiva admite demoler mitos y tabúes en relación con el desempeño de hombres y mujeres y, potencialmente, posibilita la revisión de los discursos planteados en las narrativas de autoría masculina en Hispanoamérica; como critica del sistema de inclusiones y exclusiones en el que se determinan la asignación de espacios a los individuos y, en consecuencia, han delimitado las imágenes y las expectativas en torno a ellos, lo cual es perceptible, obviamente, en el discurso literario desde el tratamiento que Raúl Dorra le da a la reconstrucción de la mujer, partiendo de la resignificación de la representación de la samaritana aludida en el evangelio de San Juan 4: 9-10 (RVR1960) en relación y critica a la formación de las diversas manifestaciones femeninas y masculinas. Por ello, para contribuir en las investigaciones sobre los problemas o temas actuales de teoría y crítica, me propuse el estudio de las masculinidades y feminismos presentes en la narrativa del autor argentino.

Cabe señalar que a pesar de que la teoría y la crítica literarias feministas son una práctica de análisis e interpretación textual de reciente aparición, comparada con la hermenéutica y la crítica psicoanalítica estructuralista o marxista, se identifican por una variedad ideológica, temática y metodológica. Sin embargo, puede decirse que esta misma multiplicidad es, en diversos sentidos, una de sus fortalezas y sin duda es la proximidad crítica a la literatura; un sinfín a la que en 


\section{ARTÍCULOS}

cierta medida está obligada porque la particularidad de los problemas que analiza y de las cuestiones que se manifiesta exigen a la interdisciplinariedad.

La importancia de recurrir a un método interdisciplinario deriva de uno de los pilares de la crítica feminista: el texto literario no puede concebirse separado del medio sociocultural determinado en el que se origina, transita y lee. Por otro lado, las críticas feministas han adquirido un impacto en el escenario de los estudios literarios académicos: al implantar nuevos instrumentales de estudios en la investigación de la literatura -como el concepto de género o de interseccionalidad-Han logrado una tremenda influencia en disciplinas como, la filosofía, los estudios culturales, la sociología, los estudios del cine, la historia y la antropología (MC Nabb et al., 2001,107).

Por ello, se considera importante abundar en el tema del género. Cabe señalar que las discusiones sobre el género han estado presentes en los últimos cincuenta años; por ejemplo, los estudios sobre las precursoras del feminismo en muchas tradiciones literarias como sor Juana Inés de la Cruz y Rosario Castellanos; dichos estudios sobre la mujer están íntimamente relacionados con los términos de minoría y de marginalidad. Por ello se vuelve la mirada hacia las obras de escritoras, rescatándolas del silencio, del abandono o del descrédito, y se hace habitualmente en estudios, historias y antologías independientes, segregadas de la historia literaria legitimada, que se ofrece como objetiva neutral, aunque en sus páginas solo se encuentren escritores sin dar cabida a la posibilidad de significar las nuevas formas de concebir al feminismo y por consecuencia el papel de los escritores en el siglo XXI. 


\section{ARTÍCULOS}

\section{Metodología}

Con antelación, en el transcurso de los años, se ha manifestado el hecho de que la teoría literaria feminista no es, ni ha sido nunca, una teoría unificada, con un cuerpo restringido de obras, que brinda un cúmulo de técnicas y conocimientos precisos para investigaciones de los rasgos, propiedades y funciones formales y temáticas de los diferentes tipos de texto que existen, y los procedimientos, esqumas y destrezas para darles significado con "perspectiva feminista", ya que constan teorías: literaria feminista marxista, posestructuralista, narratológica, estructuralista, poscolonial, psicoanalítica, deconstruccionista y neohistoricista, bajtiniana, por mencionar algunas. Empero, esta pluralidad, cabe señalar que las teorías literarias feministas son teorías de la lectura y la interpretación.

Es menester puntualizar que según las teorías literarias feministas sostienen que el sentido de cada texto puede ser determinado en correspondencia con sus contextos específicos de escritura y recepción. Inclusive, aquel análisis que se considere "más inocente", por limitarse a elementos intrínsecos y textuales, como metáforas, aliteraciones, tramas, tipos de narrador, etcétera, beneficia una idea exclusiva de la literatura que, a su vez, promueve una forma de concepción del mundo.

Debido a ese interés la investigación que desarrollé se inscribe dentro del plano de la literatura hispanoamericana; con enfoque en Estudios Culturales. Se realizó un análisis cultural de la Tierra del Profeta, bajo las siguientes fuentes teóricas: "intertextualidad" (Bajtín y Kristeva) el “Mimesis I, II Y III" (P. Ricoeur), como vías de estudio e identificación de la resignificación de personajes y pasajes 
| Cuatrimestral Facultad de Humanidades Campus VI Reserva de Derechos al Uso Exclusivo No.: 04-2018-060814012200-203| ISSN: 2594-1755 Año II | Número 6 | Mayo- Agosto 2019

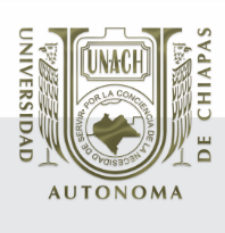

\section{ARTÍCULOS}

La literatura admite, por otro lado, la representación de las zonas negadas al sujeto, alterando la ideología dominante (las identidades nacionales, sexuales, políticas, etc.) como los discursos que mitiga. Esa doble voz actuaría en la versión de Genovese como una estrategia literaria -consciente o no- en la que se pueden identificar ciertas constantes. Si la primera voz, la depositaria de la tradición patriarcal, habita en la superficie de la novela, en sus personajes; la segunda, más conflictiva, queda enterrada. Pero, como si de un lapsus se tratara, esta segunda voz que el texto silencia deja huellas en la superficie que pueden rastrearse y que dan cuenta de su existencia. La segunda voz es una «voz en sordina» donde habita $(1998,16)$ :

Un sujeto que niega, pero también afirma, que va constituyendo a través de la escritura una identidad propia como un lugar tentativo, demasiado inestable para ser considerado una esencia. Zona de vacilación e intemperie, de Carnaval negro carencia y tambaleo, de embozada o abierta reacción; lugar titubeante el de esta identidad que no es una sino posible y múltiple.

La segunda voz organiza, sobrescribe y rescribe a la inicial, más próxima a la discursividad social dominante. Esta "doble voz", es una forma de respuesta que requiere un ejercicio de decodificación crítica cuyo propósito no es ni ablandar ni naturalizar los textos. Sus tensiones intertextuales permiten la resemantización del sujeto femenino dentro del "discurso masculino", sobre el que proyecta un nuevo imaginario en la existencia de la pluralidad de femineidad y masculinidad.

Los fundamentos anteriormente referidos, servirán para encaminar el estudio de género desde el discurso literario de La tierra del profeta, y la resignificación 
| Cuatrimestral Facultad de Humanidades Campus VI

Reserva de Derechos al Uso Exclusivo No.: 04-2018-060814012200-203| ISSN: 2594-1755

Año II | Número 6 | Mayo- Agosto 2019

\section{ARTÍCULOS}

cualquier posible rastro de esa persona: "normas de masculinidad o feminidad". Esto permite cuestionar la relación que hay entre obedecer al género y la fuerza. ¿Qué es una mujer? ¿Qué es la masculinidad? ¿Qué es la feminidad?, ¿Qué es la heterosexualidad?, ¿Qué es la homosexualidad?, ¿Cómo sería todo aquello que queda fuera de lo que establece tales alternativas?

Tendremos ocasión de decir que te faltó el ejemplo y el impulso. Mira que el Reino se hace fuerza porque es la hora en que te debes armar para el combate. Sé que tu padre no alcanzó a hacer de ti un soldado del Señor y por esa razón él se lamentaba en la hora de su muerte (1997:228).

Reflexionar sobre las identidades, el nombre, sobre una política del nombre que no está fundada sobre una identidad estable. No está fundada sobre una identidad eterna, no presupone una identidad; permite reflexionar sobre la evidencia perdida de las normas. Por ejemplo, el que una mujer se nombre Ana, es de tal nacionalidad, es ciudadana, es estudiante etc., no hay una sola identidad, no se pertenece a una sola identidad, no pertenece a una sola, sino que existe un constante transitar.

El género de una persona es una construcción social y cultural de las diferencias sexuales. A partir de ello se construyen los conceptos de masculinidad y feminidad, lo cual varía de un grupo social a otro y de una época a otra (Guzmán Ramírez, 2010 p.23).

La categoría género aborda esta dinámica de interdependencia y hace posible comprender si en un grupo social determinado estas relaciones son de

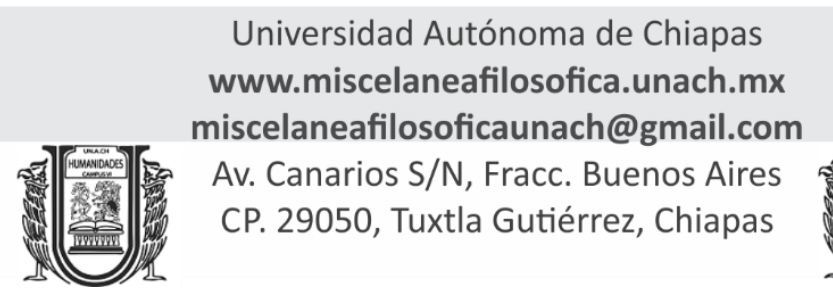


| Cuatrimestral Facultad de Humanidades Campus VI Reserva de Derechos al Uso Exclusivo No.: 04-2018-060814012200-203| ISSN: 2594-1755 Año II | Número 6 | Mayo- Agosto 2019

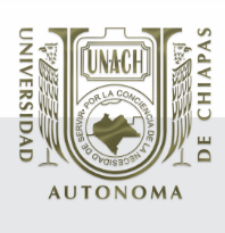

\section{ARTÍCULOS}

Según el autor la figura de la samaritana tiene un doble interés, el segundo complementario del primero. Se trata de una samaritana. La relación de Samaria con Judea y Galilea era de hostilidad (pues unos y otros se reclamaban depositarios de la verdadera fe) y aquí, en este encuentro, la hostilidad está suspendida, ambos (Jesús y la samaritana) aparecen como representantes de una reconciliación. Se puede pensar que es porque se trata de una mujer. Según lo muestran los evangelios, Jesús era impaciente y hasta intolerante con los varones, y complaciente con las mujeres, de ahí que se haya dicho que el cristianismo es una versión feminizada del judaísmo. Eso me ha interesado seguir, y por eso lo propongo a Abimael como un personaje muy volcado sobre lo femenino (Dorra, 2017, 126).

En líneas anteriores que se mantienen enmarcados bajo la tradición judeocristiana y hábilmente resignificados, permiten observar la estructura de oposición o diferenciación que el escritor mantiene a lo largo de su obra. El autor clarifica "de ahí que se haya dicho que el cristianismo es una versión feminizada del judaísmo", marcando una línea para reflexionar desde la interseccionalidad, ya que Yeoshua tuvo con algunas mujeres de su entorno actitudes que, ante la mentalidad de su época resultaban desde todo punto de vista escandalosas, como es el caso de la actitud asumida frente a los rechazados samaritanos, con una mujer ilegal frente a la Ley, que se encontraba junto al pozo de Jacob (Jn 4, 1-42).

Es interesante notar lo anterior, la respuesta pudo haber hecho alusión sólo a su condición étnica, sin embargo, ella hace alusión de la misma manera a su condición sexual: mujer. Este versículo contiene, asimismo, una nota aclaratoria

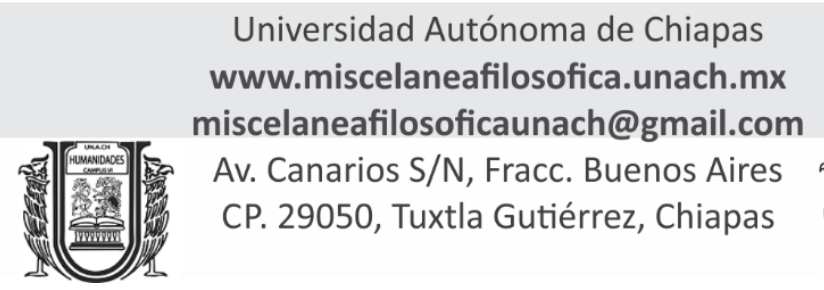


| Cuatrimestral Facultad de Humanidades Campus VI Reserva de Derechos al Uso Exclusivo No.: 04-2018-060814012200-203| ISSN: 2594-1755

Año II | Número 6 | Mayo- Agosto 2019

\section{ARTÍCULOS}

Guzmán Ramírez, Gezabel y Martha Bolio Márquez. Construyendo la herramienta perspectiva de género: cómo portar lentes nuevos México: Universidad Iberoamericana, 2010.

Maquieira D’Angelo, Virginia. Género, diferencia y desigualdad. Madrid: Alianza, 2012.

Núñez Noriega, G. "Los hombres y el conocimiento. Reflexiones epistemológicas para el estudio de los hombres como sujetos genéricos". En: Desacatos: Vol. 8 n¹6 (2004):13-32.

ONU, Desigualdad de género en el mundo, en http://www.ONUwomen.org/es/, (consultado 16 de marzo 2018).

Kristeva, Julia. La cultura popular en la Edad Media y el Renacimiento. El contexto de François Rabelais. Madrid: Alianza, 2005.

Kristeva, Julia. El texto de la novela. Barcelona: Lumen, 1984.

Ponce, Patricia. "Masculinidades diversas". En: Desacatos, Vol. 18 n 16, (2004): 7-9.

Santa Biblia. Versión de Casiodoro Reina (1569) Revisada por Cipriano Valera (1602). Philadelphia, Pensilvania, USA: Sociedades Bíblicas en America Latina, National Publishing Company, revisión 1960,

Torres, Ana. Historias del continente oscuro. Ensayos sobre la condición femenina.

Caracas: Editorial Alfa, 2007. 
| Cuatrimestral Facultad de Humanidades Campus VI Reserva de Derechos al Uso Exclusivo No.: 04-2018-060814012200-203| ISSN: 2594-1755

Año II | Número 6 | Mayo- Agosto 2019

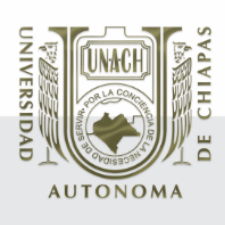

\section{ARTÍCULOS}

Tubert, Silvia. "Introducción. La crisis del concepto de género", En: Del sexo al género. Los equívocos de un concepto, editado por Silvia Tubert, ed. Madrid: Ediciones Cátedra Primera edición, 2001, 7-37.

Zavala, Iris. "Breve historia feminista de la literatura española (en lengua castellana)"En: I. Teorías feministas: discursos y diferencias, editado por Myriam Díaz Diocaretz e Iris M. Zavala coords. Madrid: Anthropos /Comunidad de Madrid, 1993, 13-76 